Article

\title{
A Measurement System for Quasi-Spectral Determination of Absorption and Scattering Parameters of Veterinary Tissue Phantoms
}

\author{
Paulina Listewnik $^{1, *(\mathbb{D}}$, Michał Wąsowicz ${ }^{2, *}$, , Monika Kosowska $^{1}\left(\mathbb{D}\right.$ and Adam Mazikowski ${ }^{1}$ \\ 1 Department of Metrology and Optoelectronics, Faculty of Electronics, Telecommunications and Informatics, \\ Gdańsk University of Technology, 11/12 Narutowicza Street, 80-233 Gdańsk, Poland; \\ nika.kosowska@gmail.com (M.K.); adamazik@pg.edu.pl (A.M.) \\ 2 Department of Morphological Sciences, Faculty of Veterinary Medicine, Warsaw University of Life Sciences, \\ 159 Nowoursynowska Street, 02-776 Warsaw, Poland \\ * Correspondence: paulist@o2.pl (P.L.); michal.wasowicz@interia.eu (M.W.); \\ Tel.: +48-58-347-1084 (P.L.); +48-225-936-010 (M.W.)
}

Received: 30 January 2019; Accepted: 15 April 2019; Published: 19 April 2019

check for updates

Featured Application: The paper presents a proposal of a measurement system for determination of optical parameters of the phantoms imitating animal tissues. The system can be used in veterinary medicine to ensure compliance of phantoms properties with the properties of live tissues.

\begin{abstract}
This paper describes the construction of a system for the quasi-spectral determination of absorption and scattering parameters of animal tissue phantoms. Several tissue phantoms, including one reference and two modified for examination, were prepared from polydimethylsiloxane (PDMS). The phantoms were measured using a system based on an integrating sphere and the light sources of wavelengths commonly used for the treatment of various diseases in veterinary medicine, including $635 \mathrm{~nm}$ (red), $532 \mathrm{~nm}$ (green) and $447 \mathrm{~nm}$ (blue). The obtained results are consistent with data provided in reference sources and can also be approximated for the entire spectral range of visible radiation (380-780 $\mathrm{nm}$ ). The developed system is suitable for further measurements of phantoms, which can be adapted to imitate different tissues.
\end{abstract}

Keywords: integrating spheres; optical parameters; tissue phantoms; phantom scattering parameters; veterinary medicine

\section{Introduction}

Animal treatment with the use of modern technologies utilizing light has become increasingly popular in veterinary medicine. One of the most significant groups of therapies is laser treatment, especially low-level laser therapy (LLLT), which includes cases of treatment of open, sterile and infected wounds, as well as acute and chronic inflammatory lesions [1,2]. To aid in the treatment of various afflictions, laser radiation from a wide range of the visible spectrum is used.

A radiation wavelength of $635 \mathrm{~nm}$ is used to accelerate the healing of soft tissues in acute and chronic inflammatory conditions and during postoperative treatment [2]. Lasers with an operational wavelength of $532 \mathrm{~nm}$ are useful in eliminating superficial vascular skin changes, e.g., bruises, ecchymosis and decubitus [3], as well as the treatment of diverse pathomorphological prostatitis inflammation in the male species belonging to Canis lupusf. domestica [4-6]. Lasers with a wavelength of $447 \mathrm{~nm}$, however, are used for intravascular laser biostimulation (ILB) during the treatment of bacterial and viral diseases. ILB was successfully used to fight hepatitis $C$ viruses and to treat diseases caused by spirochetes, e.g., Lyme disease. To date, the assessment of the effectiveness of combining 
the $447 \mathrm{~nm}$ wavelength with photosensitization indicates even larger prospective applications of this wavelength [7]. Research regarding the visual inspection of tissues, e.g., the operative field, is also currently being conducted [8].

Because veterinary medicine requires multiple ranges of the visible spectrum wavelengths to treat a variety of diseases, this paper focuses on the utilization of three wavelengths-each from a different range.

While treating tissues, preliminary examinations are performed on optical phantoms-materials mimicking the selected optical parameters of tissue $[9,10]$. The utilization of optical phantoms, in either medicine or veterinary medicine, eliminates the necessity of upholding bioethical principles and laboratories, in which the tests are performed, do not have to comply with strict norms [11]. Optical phantoms are also very durable. Unlike real tissues, they are resistant to degradation and therefore preserve their optical parameters-which is beneficial during the long-term examination of the relationship between light and matter [12,13].

Understanding the interaction between light and matter is crucial when developing light-based technologies, especially for applications in medicine. Thus, research groups are employing various optical methods for tissue and tissue phantom characterization. The dynamic laser speckle technique was used to evaluate the viability of tissues by performing ex vivo measurements on healthy and burned skin tissue [14]. The optical properties of a skin microcirculation phantom were investigated by means of Laser Doppler flowmetry utilizing self-mixing interferometry, enabling the generation of flow maps [15]. Diffuse optical tomography combined with the utilization of the optomechanical technique allowed for the accurate detection of pathological changes mimicked by a phantom [16].

Important optical parameters affecting the propagation of optical radiation in a medium are the refractive index $\mathrm{n}$ and the absorption coefficient $\mu_{\mathrm{a}}$. In case of high-scattering media, like biological matter (tissues) or their artificial equivalent (optical phantoms), very important parameters are also the scattering coefficient $\mu_{\mathrm{s}}$ and the scattering anisotropy $g$, or the reduced scattering coefficient $\mu_{\mathrm{s}}{ }^{\prime}=\mu_{\mathrm{s}}(1-g)$ [17]. Knowing the absorption and scattering parameters allows us to analyze, model and understand phenomena occurring in the tissue during its interaction with light radiation, which is essential for medical diagnosis and the evaluation of a laser's influence on the tissue.

The determination of the absorption and scattering coefficients can be performed with a measurement setup using frequency domain near-infrared spectroscopy [18], a frequency domain imaging system [19] or a broadband spectroscopy setup [20]. Goniometric methods [21] or the utilization of integrating spheres [22-24] are also commonly used. Goniometric techniques allow for the establishment of the directional distribution of scattered radiation. For materials of a substantial thickness, however, the directional characteristic exhibits a near-Lambertian distribution due to the blurring of directional properties. Moreover, obtaining the total scattered flux requires numerical integration over the entire hemisphere, i.e., employing the measured directional distribution of scattered radiation.

Measurements using integrating spheres can be performed in configuration with one or two spheres. When using two spheres, advanced algorithms have to be used to eliminate the influence of the spheres on one another (especially during measurements with wide sample ports) $[9,25]$. This problem can be solved by using only one sphere. In this case, the sample is examined for two modes of operation-transmissive and reflective. The absorption coefficient and reduced scattering coefficient can be calculated based on the Kubelka-Munk model [26].

Scattering parameters are mainly dependent on the wavelength, therefore selecting the right wavelength for a measurement is crucial. The spectrometer measurements require a broadband light source, which must be properly collimated-which is even challenging in some commercial solutions. Furthermore, the power of such a beam is highly limited, which, when combined with popular miniature spectrometers (with low sensing ability), causes low spectral power density. Therefore, detection setup noise influences the results. 
In this paper, a measurement system for the quasi-spectral determination of absorption and scattering parameters of tissue phantoms for veterinary applications is presented. This solution is characterized by a relatively simple configuration and data analysis. Moreover, an acceptable alternative for spectral measurements is provided, allowing for the determination of the absorption and scattering parameters for a set of selected wavelengths which are used in veterinary medicine.

\section{Measurement Setup and Method}

The measurement system was constructed using a 4P-GPS-053-SL (Labsphere Inc., North Sutton, $\mathrm{NH}, \mathrm{USA})$ integrating sphere. The internal diameter of the sphere is 5.3 in $(13.46 \mathrm{~cm})$, while the sample port diameter is 1 in $(2.54 \mathrm{~cm})$ [27]. The sphere utilizes a Spectralon ${ }^{\circledR}$ coating (Labsphere Inc., North Sutton, NH, USA), which provides a highly reflective surface-a diffuse reflection coefficient of above $99 \%$ for wavelengths from 400 to $1500 \mathrm{~nm}$. Laser modules (Roithner Lasertechnik, Vienna, Austria) of red, green and blue radiation were used as the light sources during this investigation, i.e., a laser diode module with a wavelength of $635 \mathrm{~nm}$ (LDM635-03-08X25, red), a diode pumped solid state (DPSS) laser module operating on the second-harmonic with a wavelength of $532 \mathrm{~nm}$ (CW532-5-831, green) and a laser pointer with a wavelength of $447 \mathrm{~nm}$ (GLP-447-20, blue). These laser sources were supplied by voltages of $3 \mathrm{~V}$ (red), $3.3 \mathrm{~V}$ (green) and $4.7 \mathrm{~V}$ (blue). To ensure power stability for the standard GLP-447-20 laser pointer, the $2 \times 3 \mathrm{~V}$ CR2 battery power supply was replaced by a laboratory power supply and the voltage was reduced to $4.7 \mathrm{~V}$.

All light sources utilized during the examination are of wavelengths within the visible spectral range [28]. They are also used for animal treatment in veterinary medicine. To ensure the accuracy and repeatability of the performed measurements, an L-100 luxmeter with a dedicated measuring head (Sonopan, Białystok, Poland) was used as a detector. The measuring head of a luxmeter has a Lambertian input characteristic. The white calibration plate CS-A21 (Konica Minolta, Tokyo, Japan) was used as a reflectance standard (reflection coefficient-96.9\%) [29]. The measurement system scheme is presented in Figure 1.
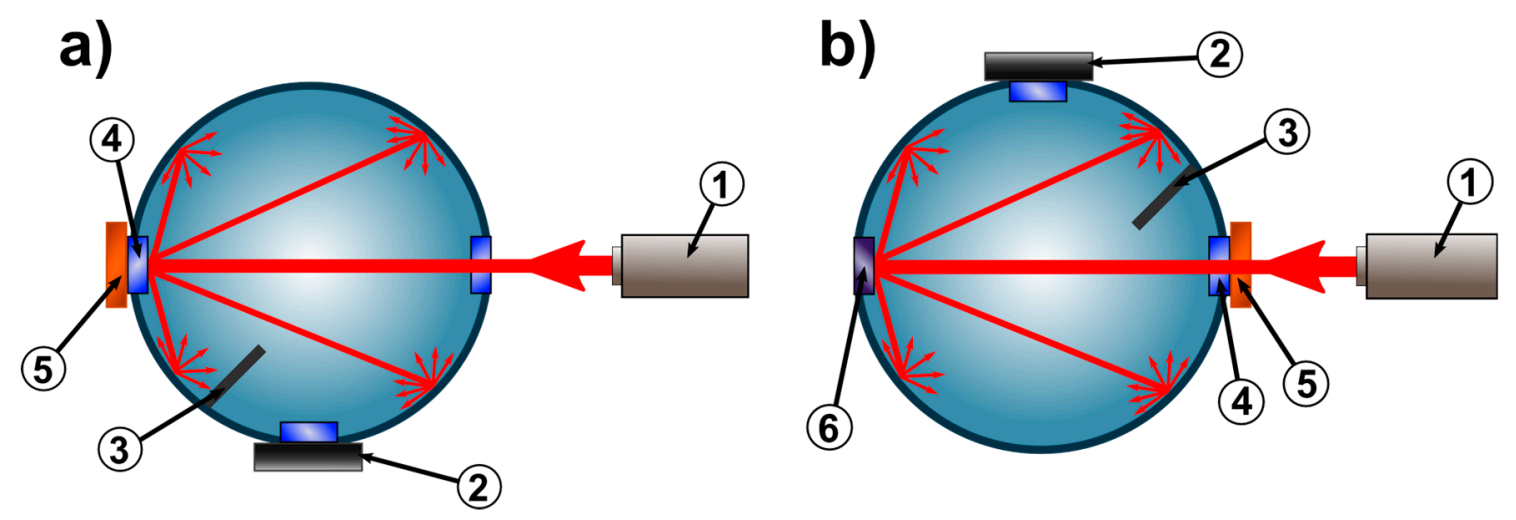

Figure 1. Measurement system. (a) Mode for the measurement of diffuse reflectance $R_{\mathrm{d}}$, (b) mode for the measurement of diffuse transmittance $T_{\mathrm{d}}$. 1-Light source, 2-detector, 3-baffle, 4-sample port, 5 - examined sample, 6-unused plugged port.

The integrating sphere, the light source and the luxmeter measuring head were precisely mounted on a $15 \times 60 \mathrm{~cm}$ optical breadboard (Thorlabs, Newton, NJ, USA) to provide acceptable system stability, which allows for the acquisition of accurate results. Furthermore, the integrating sphere can be rotated around its own axis, which helps to quickly change between configurations for transmittance and reflectance measurement. The stoppers, properly set on either side of an integrating sphere, guarantee that the sphere rotates exactly $180^{\circ}$.

The determination of scattering and absorption coefficients of a sample are based on relative measurements (absolute output is not very significant, provided it is in the sensitivity range of the 
detector). However, before performing measurements, each source was turned on for approximately $30 \mathrm{~min}$ (45 min in case of the blue source) for stabilization of the thermal condition. Room temperature was stabilized to $23{ }^{\circ} \mathrm{C}$ with an accuracy of $1{ }^{\circ} \mathrm{C}$. Additionally, the aforementioned quick change between configurations allowed us to take measurements within a short amount of time (1-2 min), which is a key factor for relative measurements. The system operator aimed to eliminate all possible external light sources to maintain un-biased results. Therefore, all lighting was obscured during measurements. Figure 2 presents the physical implementation of the measurement system.

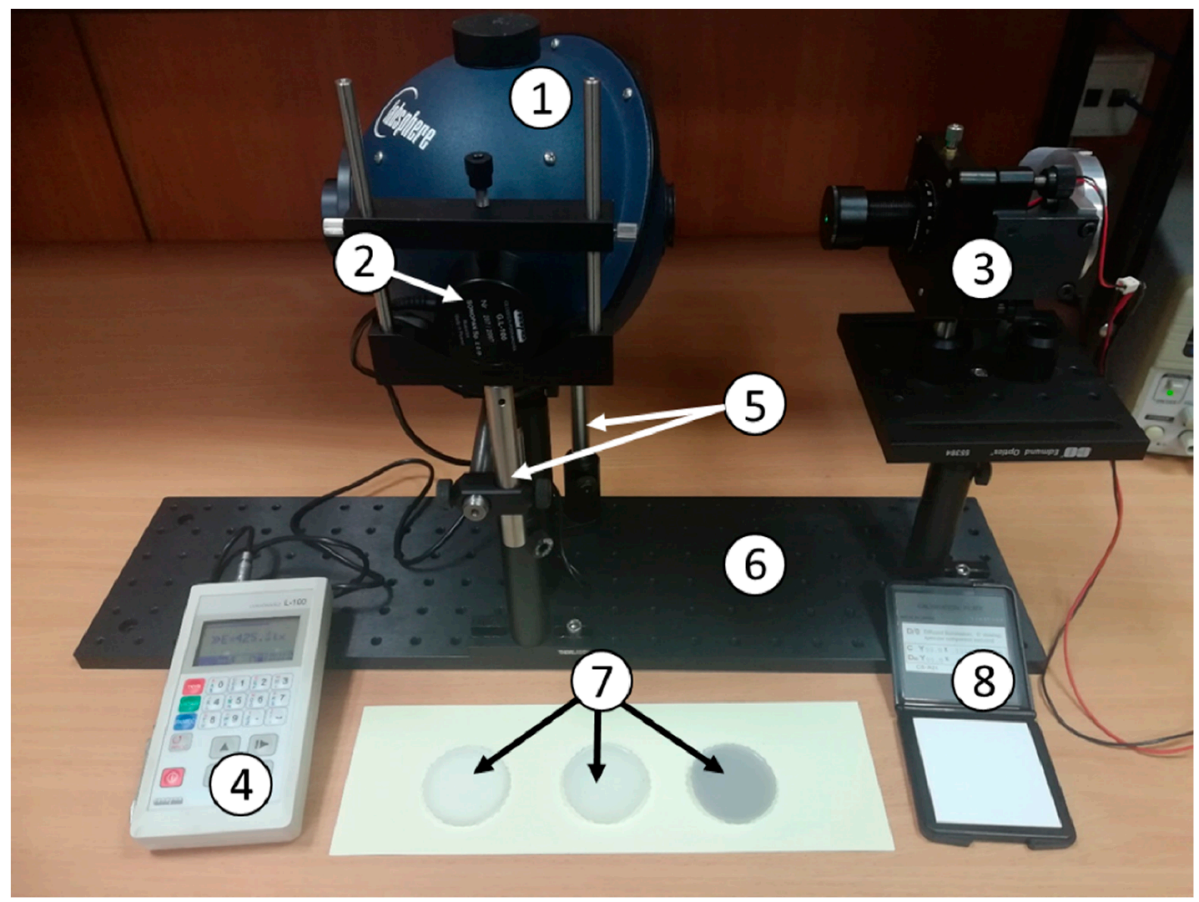

Figure 2. Setup for the measurement of diffuse reflectance $R_{\mathrm{d}}$. 1 -integrating sphere Labsphere, 2-luxmeter measuring head, 3-light source, 4-luxmeter, 5-rotation stoppers, 6-optical breadboard, 7-prepared phantoms, 8 - white calibration plate CS-A21 by Konica Minolta.

To verify the correct operation of the system, measurements of diffuse reflectance and transmittance were executed. Furthermore, the coefficients of reduced scattering and absorption in a few scattering media (phantoms) were calculated [30]. Examined phantoms were prepared from the silicon-based organic polymer polydimethylsiloxane (PDMS) (Sylgard ${ }^{\circledR}$ 184, Dow Corning, Midland, MI, USA) and high clarity glycerol (Sigma-Aldrich, St. Louis, MO, USA). The details were described by Wróbel et al. [30]. All the samples were disks with a diameter of $45 \mathrm{~mm}$ and a thickness of 2-2.6 mm. One of the phantoms (A) was a reference sample with known parameters. Various amounts of India ink were added to the two remaining samples $(B, C)$ to pre-evaluate the possibility of increased absorption of these samples, as the estimated absorption of the reference sample is small—close to zero. All the samples are shown in Figure 3.

The measurements were executed using one integrating sphere in two modes of operation: reflective and transmissive. The principle of operation in both modes is presented in Figure 1. In each configuration, the detector head is firmly installed on the $90^{\circ}$ port, while the north pole port is plugged to maintain the repeatability of measurements and to eliminate the external influence of light. At the beginning of each measurement, the CS-A21 white calibration plate was mounted to the sample port to provide a reference. The luxmeter indicator is proportional to the total power of the source $P_{\text {reference }}$. In the reflectance measurement mode, the white calibration plate is replaced with the investigated sample. In this configuration the light propagates through the reduced $180^{\circ}$ port and the sphere, illuminating the sample. Part of the radiation, reflected to the sphere $\left(P_{\mathrm{R} \text { sample }}\right)$, is measured by the 
luxmeter. Next, the sphere is rotated $180^{\circ}$ around its axis, so that the baffle changes its position for the measurement of transmittance. In this configuration, the $180^{\circ}$ port is plugged. The light directly illuminates the sample. Similarly, the luxmeter measured part of the radiation that was transmitted into the sphere $\left(P_{\mathrm{T} \text { sample }}\right)$. Figure 4 presents a block diagram of the data analysis algorithm.

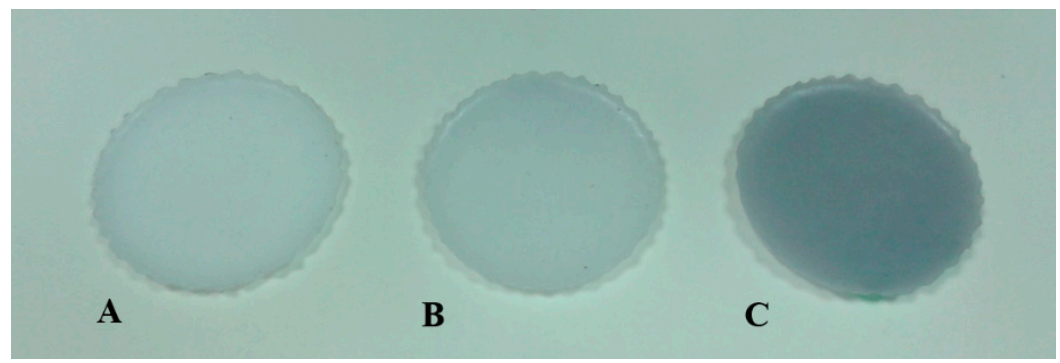

Figure 3. Produced phantoms. A-reference $\varnothing=45 \mathrm{~mm}, d=2 \mathrm{~mm}$; B-with the addition of India ink $(5 \mu \mathrm{L}) \varnothing=45 \mathrm{~mm}, d=2.6 \mathrm{~mm}$; C-with the addition of India ink $(20 \mu \mathrm{L}) \varnothing=45 \mathrm{~mm}, d=2.3 \mathrm{~mm}$.

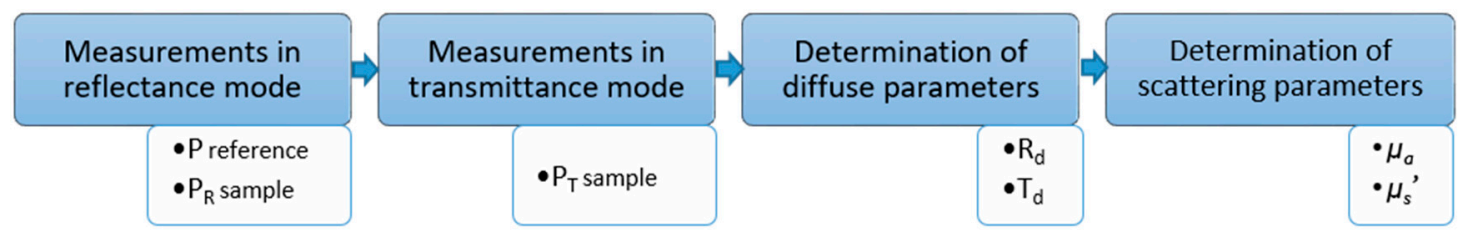

Figure 4. Block diagram of the data analysis algorithm, where $P_{\mathrm{R}}$-reference measurement using the CS-A21 white calibration plate in reflectance mode. $P_{\mathrm{R} \text { sample, }}, P_{\mathrm{T} \text { sample }}$-measurements of the investigated phantom in reflectance and transmittance modes, respectively. $T_{\mathrm{d}}$-diffuse transmittance. $R_{\mathrm{d}}$-diffuse reflectance. $\mu_{\mathrm{a}}$-absorption coefficient. $\mu_{\mathrm{s}}^{\prime}$-reduced scattering coefficient.

The obtained measurement values were used to calculate the diffuse reflectance $R_{\mathrm{d}}$ and the diffuse transmittance $T_{\mathrm{d}}$ according to Formulas (1) and (2):

$$
\begin{gathered}
R_{\mathrm{d}}=\frac{P_{\text {R sample }}}{P_{\text {reference }}} \\
T_{\mathrm{d}}=\frac{P_{\mathrm{T} \text { sample }}}{P_{\text {reference }}}
\end{gathered}
$$

where $P_{\mathrm{R} \text { sample }}$ and $P_{\mathrm{R} \text { reference }}$ are measurements in reflectance mode obtained from the investigated phantom and of the CS-A21 white calibration plate, respectively. Similarly, $P_{\mathrm{T} \text { sample }}$ is a measurement obtained by the investigation in transmittance mode. The calculated values of diffuse reflectance $R_{\mathrm{d}}$ and diffuse transmittance $T_{\mathrm{d}}$ were used as a basis for determination of absorption coefficient $\mu_{\mathrm{a}}$ and reduced scattering coefficient $\mu_{\mathrm{s}}{ }^{\prime}$ according to the Kubelka-Munk model using the following formulas [26]:

$$
\begin{gathered}
S_{\mathrm{KM}}=\frac{1}{b \cdot d} \ln \left[\frac{1-R_{\mathrm{d}} \cdot(a-b)}{T_{\mathrm{d}}}\right] \\
K_{\mathrm{KM}}=(a-1) * S_{\mathrm{KM}}
\end{gathered}
$$

where $S_{\mathrm{KM}}$-Kubelka-Munk scattering coefficient, $K_{\mathrm{KM}}-$ Kubelka-Munk is the absorption coefficient, $d$-sample thickness, and:

$$
\begin{gathered}
a=\frac{1+R_{\mathrm{d}}^{2}+T_{\mathrm{d}}^{2}}{2 R_{\mathrm{d}}}(a-1) \cdot S_{\mathrm{KM}} \\
b=\sqrt{a^{2}-1} .
\end{gathered}
$$


Finally, the absorption coefficient $\mu_{\mathrm{a}}$ and reduced scattering coefficient $\mu_{\mathrm{s}}^{\prime}$ can be calculated as:

$$
\begin{gathered}
u_{\mathrm{s}}^{\prime}=\frac{3}{4} S_{\mathrm{KM}}-\frac{1}{6} K_{\mathrm{KM}} \\
u_{\mathrm{a}}=\frac{1}{2} u_{\mathrm{s}}^{\prime}
\end{gathered}
$$

\section{Results}

The results of the measurements performed with the use of the three light sources, 635, 532 and $447 \mathrm{~nm}$ for each phantom, are presented in Table 1.

Table 1. Obtained measurement results of phantoms A, B and C.

\begin{tabular}{ccccc}
\hline Phantom & $\boldsymbol{R}_{\mathbf{d}}$ & $\boldsymbol{T}_{\mathbf{d}}$ & $\boldsymbol{\mu}_{\mathbf{a}}$ & $\boldsymbol{\mu}_{\mathbf{s}}{ }^{\prime}$ \\
\hline \multicolumn{5}{c}{ light source-635 $\mathbf{~ m ~}$} \\
A & 0.37 & 0.57 & $0.07 \pm 0.02$ & $1.67 \pm 0.05$ \\
B & 0.39 & 0.48 & $0.18 \pm 0.03$ & $2.67 \pm 0.1$ \\
C & 0.23 & 0.25 & $0.92 \pm 0.03$ & $1.83 \pm 0.1$ \\
A & 0.38 & 0.57 & $0.05 \pm 0.02$ & $1.75 \pm 0.05$ \\
B & 0.40 & 0.47 & $0.19 \pm 0.03$ & $2.75 \pm 0.1$ \\
C & 0.24 & 0.22 & $0.98 \pm 0.03$ & $2.04 \pm 0.1$ \\
A & 0.39 & 0.56 & $0.06 \pm 0.02$ & $1.83 \pm 0.05$ \\
B & 0.42 & 0.48 & $0.14 \pm 0.03$ & $2.86 \pm 0.1$ \\
C & 0.25 & 0.22 & $0.97 \pm 0.03$ & $2.11 \pm 0.1$ \\
\hline
\end{tabular}

The obtained results are consistent with those of [30]. The order of magnitude of the reduced scattering coefficient is about 1.60-1.65 for a wavelength of $635 \mathrm{~nm}$ and 1.70-1.75 for a wavelength of $532 \mathrm{~nm}$ (reference sample). Reference data presented in [30] do not include the scattering coefficient for a wavelength of $447 \mathrm{~nm}$. The values obtained from the measurements, using the system described in this paper, are 1.67 and 1.75 for wavelengths of 635 and $532 \mathrm{~nm}$, respectively. The absorption coefficient results are also consistent with reference [30] and within the range of 0.05-0.06.

The measurement results for samples $B$ and $C$ show a significant change in the absorption coefficient with the addition of small amounts of ink. However, further studies are planned to accurately determine the quantitative ink concentration.

While maintaining due diligence, the uncertainty of measurement for the reference sample (A) was estimated to be \pm 0.02 for $\mu_{\mathrm{a}}$ and \pm 0.05 for $\mu_{\mathrm{s}}{ }^{\prime}$. The estimated uncertainty of measurement for samples $\mathrm{B}$ and $\mathrm{C}$ are greater, mainly due to the noticeable non-uniformity of the thickness of these samples.

Based on the gathered data, a few relevant observations can be made. Firstly, the ability to obtain a high-scattering medium with a minimum absorption was verified. Secondly, it was found that wavelength does not influence the absorption coefficient. Furthermore, the correlation between the reduced scattering coefficient and wavelength was demonstrated. Based on the measurements of the three wavelengths, this parameter could be approximated in the spectral range.

\section{Conclusions}

A measurement system for the quasi-spectral determination of scattering parameters of veterinary tissue phantoms was constructed to examine artificial scattering media mimicking tissues-optical phantoms. The measurements were performed with the use of the three light sources: 635,532 and $447 \mathrm{~nm}$. These wavelengths were chosen because of their common applications in veterinary medicine. The data obtained from sample measurements correlate with those gathered from reference sources, 
therefore verifying the effectiveness of the described system. Furthermore, the ability to tailor the optical parameters of phantoms allows future investigation.

Author Contributions: Conceptualization, A.M. and M.W.; methodology, A.M. and P.L.; validation, A.M. and P.L.; data analysis, A.M.; investigation, A.M., P.L. and M.K.; resources, M.K. and M.W.; writing-original draft preparation, review and editing, P.L., M.W., M.K. and A.M.; visualization, M.K. and A.M.; supervision, A.M.; funding acquisition, M.W. and A.M.

Funding: This study was partially supported by DS Funds of the Faculty of Electronics, Telecommunications and Informatics of the Gdańsk University of Technology.

Conflicts of Interest: The authors declare no conflict of interest. The funders had no role in the design of the study; in the collection, analyses, or interpretation of data; in the writing of the manuscript, or in the decision to publish the results.

\section{References}

1. Gál, P.; Mokrý, M.; Vidinský, B.; Kilík, R.; Depta, F.; Harakalová, M.; Longauer, F.; Mozes, S.; Sabo, J. Effect of equal daily doses achieved by different power densities of low-level laser therapy at $635 \mathrm{~nm}$ on open skin wound healing in normal and corticosteroid-treated rats. Lasers Med. Sci. 2009, 24, 539-547. [CrossRef]

2. Vasilenko, T.; Slezák, M.; Kovác, I.; Bottková, Z.; Jakubco, J.; Kostelníková, M.; Tomori, Z.; Gál, P. The effect of equal daily dose achieved by different power densities of low-level laser therapy at 635 and $670 \mathrm{~nm}$ on wound tensile strength in rats: A short report. Photomed. Laser Surg. 2010, 28, 281-283. [CrossRef]

3. Clark, C.; Cameron, H.; Moseley, H.; Ferguson, J.; Ibbotson, S.H. Treatment of superficial cutaneous vascular lesions: Experience with the KTP 532 nm laser. Lasers Med. Sci. 2004, 19, 1-5. [CrossRef] [PubMed]

4. Malek, R.S.; Kang, H.W.; Peng, Y.S.; Stinson, D.; Beck, M.T.; Koullick, E. Photoselective vaporization prostatectomy: Experience with a novel $180 \mathrm{~W} 532 \mathrm{~nm}$ lithium triborate laser and fiber delivery system in living dogs. J. Urol. 2011, 185, 712-718. [CrossRef]

5. Qadri, T.; Miranda, L.; Tunér, J.; Gustafsson, A. The short-term effects of low-level lasers as adjunct therapy in the treatment of periodontal inflammation. J. Clin. Periodontol. 2005, 32, 714-719. [CrossRef]

6. Angelis, N.D.; Hanna, R.; Signore, A.; Amaroli, A.; Benedicenti, S. Effectiveness of dual-wavelength (Diodes $980 \mathrm{Nm}$ and $635 \mathrm{Nm}$ ) laser approach as a non-surgical modality in the management of periodontally diseased root surface: A pilot study. Biotechnol. Biotechnol. Equip. 2018, 32, 1575-1582. [CrossRef]

7. WLBK. Available online: http://fototerapialaserowa.pl/pl/wlbk.html (accessed on 22 March 2019).

8. Mundinger, J.; Houser, K. Adjustable correlated colour temperature for surgical lighting. Light. Res. Technol. 2019, 51, 280-290. [CrossRef]

9. Wróbel, M.S.; Popov, A.P.; Bykov, A.V.; Kinnunen, M.; Jędrzejewska-Szczerska, M.; Tuchin, V.V. Measurements of fundamental properties of homogeneous tissue phantoms. JBO 2015, 20, 045004. [CrossRef]

10. Wróbel, M.S.; Popov, A.P.; Bykov, A.V.; Kinnunen, M.; Jędrzejewska-Szczerska, M.; Tuchin, V.V. Multi-layered tissue head phantoms for noninvasive optical diagnostics. J. Innov. Opt. Health Sci. 2014, 8, 1541005. [CrossRef]

11. Karpienko, K.; Gnyba, M.; Milewska, D.; Wróbel, M.S.; Jędrzejewska-Szczerska, M. Blood equivalent phantom vs whole human blood, a comparative study. J. Innov. Opt. Health Sci. 2015, 9, 1650012. [CrossRef]

12. Wróbel, M.S.; Jędrzejewska-Szczerska, M.; Galla, S.; Piechowski, L.; Sawczak, M.; Popov, A.P.; Bykov, A.V.; Tuchin, V.V.; Cenian, A. Use of optical skin phantoms for preclinical evaluation of laser efficiency for skin lesion therapy. J. Biomed Opt. 2015, 20, 85003. [CrossRef]

13. Feder, I.; Wróbel, M.; Duadi, H.; Jędrzejewska-Szczerska, M.; Fixler, D. Experimental results of full scattering profile from finger tissue-like phantom. Biomed. Opt. Express 2016, 7, 4695-4701. [CrossRef]

14. Ramírez-Miquet, E.E.; Romero, L.M.M.; Darias, J.G.; Martínez-Celorio, R.A. Ex-vivo assessment of tissue viability using dynamic laser speckle. In Proceedings of the SPECKLE 2015: VI International Conference on Speckle Metrology, Guanajuato, Mexico, 24-26 August 2015; Volume 9660, p. 96601U.

15. Zakian, C.; Dickinson, M. Laser Doppler imaging through tissues phantoms by using self-mixing interferometry with a laser diode. Opt. Lett. 2007, 32, 2798-2800. [CrossRef]

16. Ali Ansari, M.; Alikhani, S.; Mohajerani, E. A hybrid imaging method based on diffuse optical tomography and optomechanical method to detect a tumor in the biological phantom. Opt. Commun. 2015, 342, $12-19$. [CrossRef] 
17. Kanick, S.C.; Gamm, U.A.; Schouten, M.; Sterenborg, H.J.C.M.; Robinson, D.J.; Amelink, A. Measurement of the reduced scattering coefficient of turbid media using single fiber reflectance spectroscopy: Fiber diameter and phase function dependence. Biomed. Opt. Express 2011, 2, 1687-1702. [CrossRef]

18. Sthalekar, C.C.; Miao, Y.; Koomson, V.J. Optical Characterization of Tissue Phantoms Using a Silicon Integrated fdNIRS System on Chip. IEEE Trans. Biomed. Circuits Syst. 2017, 11, 279-286. [CrossRef]

19. Monte, A.F.G.; Reis, A.F.; Junior, L.B.C.; Antunes, A. Preparation and quantitative characterization of polydimethylsiloxane optical phantoms with zinc-phthalocyanine dye absorbers. Appl. Opt. 2018, 57, 5865-5871. [CrossRef]

20. Shahin, A.; Bachir, W. Broadband spectroscopy for characterization of tissue-like phantom optical properties. Pol. J. Med. Phys. Eng. 2017, 23, 121-126. [CrossRef]

21. Hall, G.; Jacques, S.L.; Eliceiri, K.W.; Campagnola, P.J. Goniometric measurements of thick tissue using Monte Carlo simulations to obtain the single scattering anisotropy coefficient. Biomed. Opt. Express 2012, 3, 2707-2719. [CrossRef]

22. Moes, C.J.M.; van Gemert, M.J.C.; Star, W.M.; Marijnissen, J.P.A.; Prahl, S.A. Measurements and calculations of the energy fluence rate in a scattering and absorbing phantom at $633 \mathrm{~nm}$. Appl. Opt. 1989, 28, 2292-2296. [CrossRef]

23. Royston, D.D.; Poston, R.S.; Prahl, S.A. Optical properties of scattering and absorbing materials used in the development of optical phantoms at $1064 \mathrm{~nm}$. J. Biomed. Opt. 1996, 1, 110-116. [CrossRef]

24. Labsphere. Internationally Recognized Photonics Company. Available online: https://www.labsphere.com/ (accessed on 28 January 2019).

25. Prahl, S.A. The Adding-Doubling Method. In Optical-Thermal Response of Laser-Irradiated Tissue; Welch, A.J., Van Gemert, M.J.C., Eds.; Springer US: Boston, MA, USA, 1995; pp. 101-129.

26. Krainov, A.D.; Mokeeva, A.M.; Sergeeva, E.A.; Agrba, P.D.; Kirillin, M.Y. Optical properties of mouse biotissues and their optical phantoms. Opt. Spectrosc. 2013, 115, 193-200. [CrossRef]

27. Bhandari, A.; Hamre, B.; Frette, Ø.; Zhao, L.; Stamnes, J.J.; Kildemo, M. Bidirectional reflectance distribution function of Spectralon white reflectance standard illuminated by incoherent unpolarized and plane-polarized light. Appl. Opt. 2011, 50, 2431-2442. [CrossRef]

28. Wagnières, G.; Cheng, S.; Zellweger, M.; Utke, N.; Braichotte, D.; Ballini, J.P.; van den Bergh, H. An optical phantom with tissue-like properties in the visible for use in PDT and fluorescence spectroscopy. Phys. Med. Biol. 1997, 42, 1415-1426. [CrossRef]

29. Sensing, K.M. CS-200 Color and Luminance Meter Konica Minolta Sensing. Available online: https: //sensing.konicaminolta.us/products/cs-200-color-and-luminance-meter/ (accessed on 28 January 2019).

30. Wróbel, M.S.; Popov, A.P.; Bykov, A.V.; Tuchin, V.V.; Jędrzejewska-Szczerska, M. Nanoparticle-free tissue-mimicking phantoms with intrinsic scattering. Biomed. Opt. Express 2016, 7, 2088-2094. [CrossRef] 